\title{
Christie, Meakins and exercise intolerance in chronic airflow limitation
}

\section{NORMAN L JONES MD \\ McMaster University, Hamilton, Ontario}

$\mathrm{I}_{\mathrm{t}}^{\mathrm{s}}$ $\mathrm{t}$ was a great privilege and honour to give the Christie Lecture at the Thoracic Society Meeting in Montreal, only a stone's throw from the present-day Meakins-Christie Institute, where the tradition of innovative research established by Meakins and Christie has been so spectacularly continued. Ronald Christie (Figure 1) was a driving force in modern academic medicine, and respirology in particular, in Canada, and the link to Jonathan Meakins (Figure 2) must have been seminal, for it is certain that Meakins was a scientific father figure to Christie. When Christie was a medical student in Edinburgh, Meakins was the Christison Professor of Therapeutics; with his Lecturer, $H$ Whitridge Davies, he wrote Respiratory Function in Disease (1). Anyone writing on the pathophysiology of exercise in cardiopulmonary disorders or on dyspnea, and who thinks they have a new idea, should first check that it is not in this 1925 textbook. Meakins was clearly an important influence on Christie, and in 1934 when they were together at McGill, Christie as a junior research associate and Meakins as Professor of Medicine, they wrote a paper on "Treatment of emphysema" for the Journal of the American Medical Association (2). This put forward their ideas on the factors that limited patients, both pulmonary and cardiac. Notable in this paper is a great understanding regarding the changes in elastic recoil and lung volume, and the implications for diaphragm function in emphysema. It included the following statement, which antedates modern ventilationperfusion $\left(\mathrm{V}_{\mathrm{A}} / \mathrm{Q}_{\mathrm{c}}\right)$ concepts: "No longer are the alveoli equally ventilated, but the superficial, distended and ischemic and relatively functionless alveoli are overventilated at the expense of the deeper and more healthy alveoli, which are underventilated." There followed a series of papers on the mechanical properties of the lungs in emphysema (3), and in 1934, now Professor of Medicine at St Bart's in London, Christie delivered the Gouldstonian Lecture to the Royal College of Physicians on "Emphysema of the lungs" (4), which remains a classic to this day. This was followed in 1938 by a massive review, "Dyspnea" in the Quarterly Journal of Medicine (5). He had a great influence on young respiratory physicians in the United Kingdom; in 1956 in Britain's most prestigious internal medicine journal we find David Bates as the first author of a marvellous paper, "Respiratory function in emphysema in relation to prognosis" (6), in which a grading of dyspnea is presented, exercise capacity is studied, and the diffusing capacity for carbon monoxide is identified as the strongest predictor of both exercise capacity and prognosis. Christie and his group appear to have dominated clinical respiratory physiology in the United Kingdom in the 'forties and early 'fifties; as a young trainee, Malcolm Mcllroy wrote a series of papers with Christie on the work of breathing in emphysema, showing that it was increased and suggesting that this must contribute to dyspnea by "making the patient conscious of respiratory effort" (7). Christie and Bates then went to Montreal; Mcllroy also moved, but to the Cardiovascular Research Institute in San Francisco. 


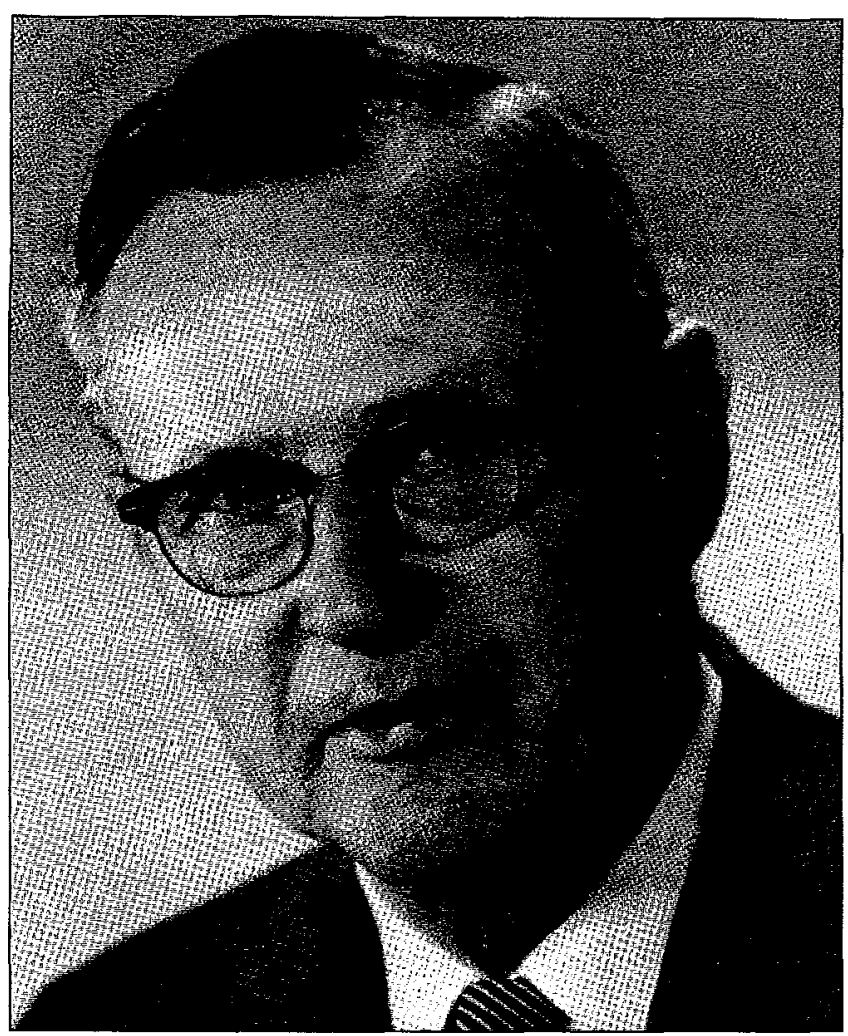

Figure 1) Ronald Christie (1902-1986)

Although Meakins and Christie identified dyspnea as the main limiting factor for patients with chronic airflow limitation, defining this symptom as "the consciousness of the need for increased respiratory effort" (8) and identifying its multifactorial origins, the main concept underlying limitation was until very recently that of the attainment of a ventilatory or gas exchange limit. This concept was formally put forward by Baldwin, Cournand and Richards in 1949 (9), and elaborated during the next 50 years; patients were unable to exercise beyond the point at which ventilation reached the maximal voluntary ventilation (MVV) or a fall in arterial $\mathrm{PO}_{2}$ impaired oxygen delivery to exercising muscle. These authors put forward the concept of breathing reserve, the ratio of maximal exercise ventilation to MVV, later elaborated into the 'dyspnea index' by Hugh-Jones and Lambert (10) and into a method to predict exercise capacity in patients with chronic obstructive lung disease (COLD) by Armstrong et al (11).

\section{WHAT IS MVV?}

The maximal achievable ventilation or maximal breathing capacity (MBC) was initially measured by having the subject breathe as much as possible with a closed circuit spirometer system, usually for $15 \mathrm{~s}$. Later, it was realized that $\mathrm{MBC}$ measured in this way represented a sprint performance and was greater than sustainable MVV (12), and MVV became more commonly estimated from measurements of forced expiratory volume in $1 \mathrm{~s}$ (FEV 1 ) by multiplying by 35 or 40 . While this practice has stood the test of time, relationships

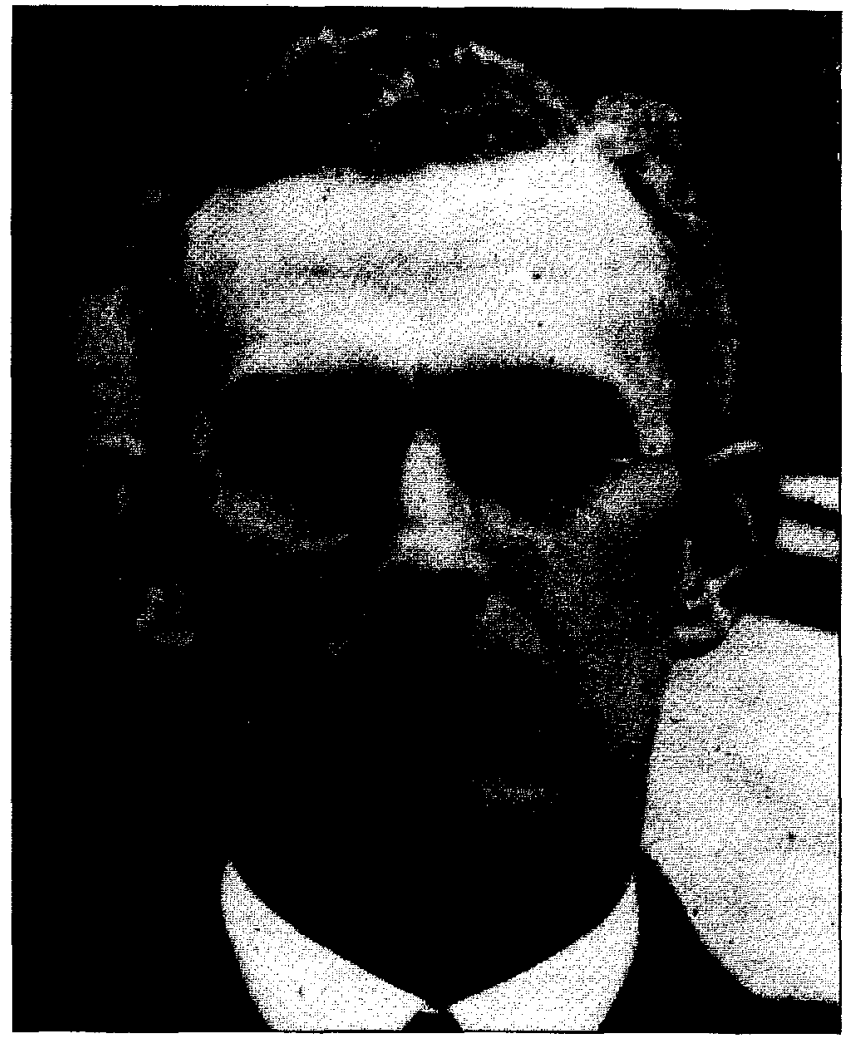

Figure 2) Jonathan Meakins (1882-1859)

between MVV and maximal exercise ventilation tended to be quite variable, and at low levels of $F_{1}$, the MVV was often exceeded (13). At least in part, this finding was explained by inspiratory flow being less impaired than expired (Figure 3), leading to a recommendation that both $F E V_{1}$ and maximal inspiratory flow be used to estimate MVV (14). However, the capacity to breathe during exercise is influenced by many factors, only some of which may be assessed by spirometry at rest.

\section{VARIATION IN THE VENTILATORY RESPONSES TO EXERCISE}

While exercise limitation due to reductions in ventilatory capacity was a useful concept, and there was a general relationship between reductions in $\mathrm{FEV}_{1}$ and maximum power output, there was a large variability, with many exceptions in both directions. Some patients with very low FEV1 (say, below 1.0 L) showed a normal exercise capacity, and conversely some patients were extremely disabled in spite of relatively normal MVV. At least some of this variability could be related to differences in the ventilatory responses to exercise; thus, many disabled patients showed a higher ventilation than expected, and some who were less disabled showed a lower response.

Considering the homeostatic function of breathing, acting to maintain blood gases between tolerable limits in the face of increases in metabolic consumption of oxygen, a number of factors may be recognized as influencing ventilation ( $\dot{V} E$ ) at any given level of exercise. 


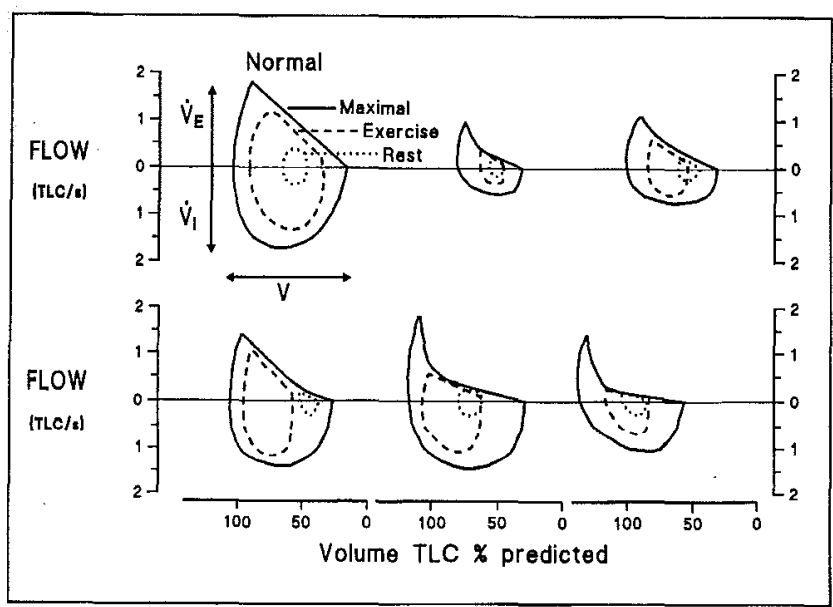

Figure 3) Flow/volume loops in a normal subject and five representative patients with chronic obstructive lung disease. Maximal flow at rest is shown as the outer loop; inner loop is resting tidal flow; final loop is in maximal steady state exercise. Note variable flow in inspiration $(\dot{V})$ as well as expiration $(\dot{V} E)$ in patients, with excellent inspiratory flow in spite of severe expiratory reduction in some, and with a loss of the normal reduction in end-inspired lung volume during exercise (43). TLC Total lung capacity

Variations in carbon dioxide production: Increases in carbon dioxide production $\left(\mathrm{V}_{\mathrm{CO}_{2}}\right)$ as a result of a greater proportion of metabolism from glycogen than fat are due to complex regulatory factors, hormonal or biochemical in origin, including insulin, glucagon and catecholamine secretion and variations in the activity of rate-limiting enzymes in the exercising muscle. Such factors also contribute to lactate production, which indirectly leads to carbon dioxide evolution. These factors increase the respiratory exchange ratio (RER), leading to increases in $\dot{V}_{E}$, and explain the reductions in exercise capacity following a meal (15) or a glucose load (16) in patients with COLD, and the reductions in $\dot{V} E$ following exercise training (17). The importance of muscle oxidative enzyme activity in patients with COLD has been emphasized recently (18).

Variations in the response of alveolar ventilation: Even in the healthy population, arterial $P_{2} \mathrm{CO}_{2}$ varies between 35 and $45 \mathrm{mmHg}$, which at a moderate work load (carbon dioxide of $2 \mathrm{~L} / \mathrm{min}$ ) implies an alveolar ventilation $\left(\dot{V}_{A}\right)$ of 38 to 50 $\mathrm{L} / \mathrm{min}$. The variation in patients with COLD is much larger, $\mathrm{PaCO}_{2}$ during exercise being less than $30 \mathrm{mmHg}$ in some and above 70 in others (19). Variations in gas exchange capacity and ventilation-perfusion matching account for some of these variations, but differences in the work of breathing and in respiratory control mechanisms are also known to be important (20).

Variations in dead space ventilation: The concept of dead space, influencing total ventilation for given carbon dioxide outputs and $\dot{V}_{A}$, has been used to explain variations in the ventilatory response to exercise in terms of ventilation-perfusion mismatching. Christie well understood the implications: "The emphysematous patient is indeed in an unfortunate position. Both inspiration and expiration have to be executed by unnatural respiratory efforts, and a considerable propor-

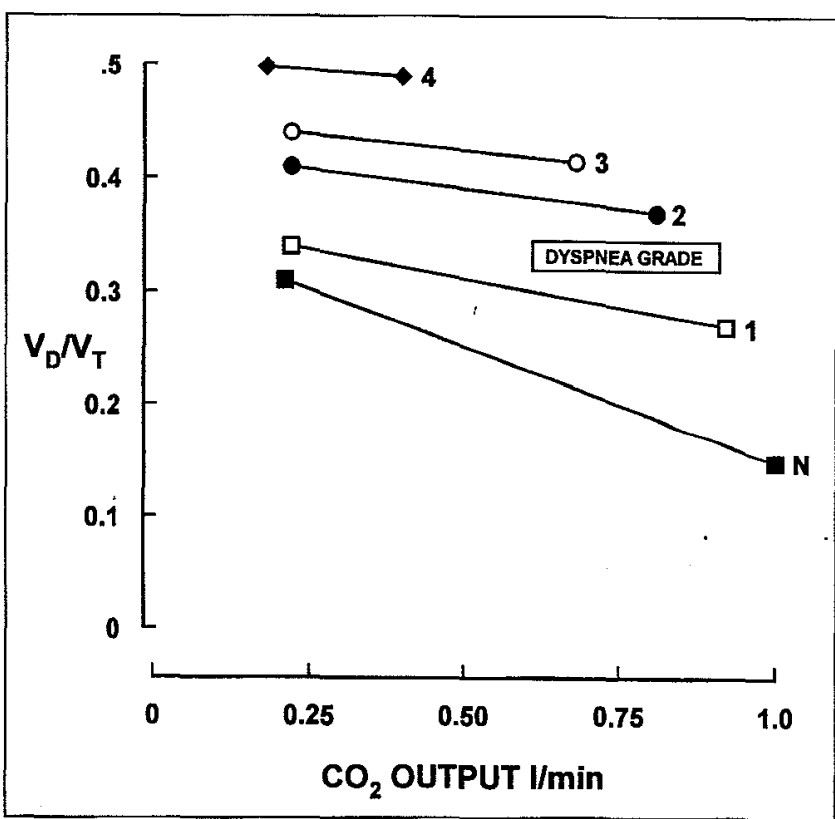

Figure 4) Dead space/tidal volume ratio $\left(V_{D} V_{T}\right)$ at rest and exercise in patients with chronic obstructive lung disease grouped according to severity of dyspnea (United Kindgom Medical Research Council grades 1 to 4 ), showing increasing $V_{D} V_{T}$ at rest, and with lessening reduction in exercise in patients with increasing dyspnea grade (21). N Normal subject

tion of the air which is inspired is wasted by not coming into proper contact with the pulmonary blood" (5). Thus, patients with well-ventilated, poorly perfused areas in the lung tend to have higher ventilation; also, a shallow pattern of breathing leads to wastage of ventilation, a high dead space ventilation to tidal volume ratio $\left(\mathrm{VD}_{\mathrm{D}} / \mathrm{V}_{\mathrm{T}}\right)$, resulting merely from a low $\mathrm{V}_{\mathrm{T}}$. Normally, $\mathrm{V}_{\mathrm{D}} / \mathrm{V}_{\mathrm{T}}$ falls during exercise from around 0.3 to less than 0.1 , but in many patients the ratio is as high as 0.6 and may not fall during exercise. $\mathrm{V}_{\mathrm{D}} / \mathrm{V}_{\mathrm{T}}$ was shown to contribute to dyspnea independent of the degree of airflow obstruction (Figure 4) (21).

The effects of these three factors on $\dot{V} E$ may be expressed in an equation that combines metabolism (oxygen and RER), $\dot{V}_{A}$ (reflected in $\mathrm{PaCO}_{2}$ ) and dead space:

$$
\dot{\mathrm{V}} \mathrm{E}=\frac{\dot{\mathrm{V}}_{2} \times 0.86 \mathrm{RER}}{\mathrm{PaCO}_{2}(1-\mathrm{VD} / \mathrm{VT})}
$$

which helps us to understand why $\dot{V} E$ may be so variable among different individuals during exercise. Increases in $\dot{V} E$ contribute as much to dyspnea in COLD as reductions in MVV (Figure 5).

Different types of COLD syndromes: Soon after I became a registrar in chest medicine at the Hammersmith in 1961, I was drawn into discussions regarding clinical and physiological differences between patients with chronic airflow obstruction who were 'pink and puffing' with evidence of emphysema, and those who were 'blue and bloated' and often did not show any emphysema physiologically or post mortem (22). Striking in this comparison was a difference in dyspnea and exercise limitation, both of which were much increased 


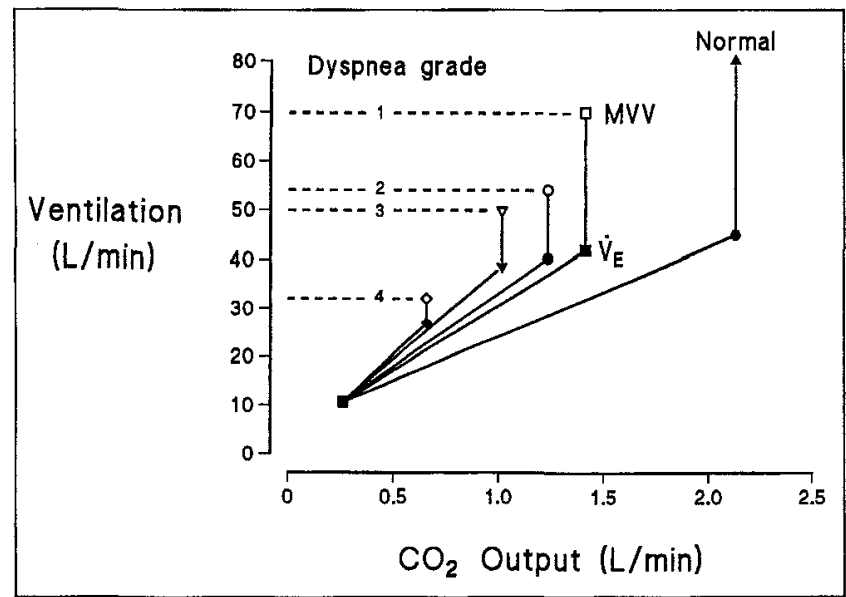

Figure 5) Ventilation in relation to carbon dioxide output in the same patients as in Figure 4; ventilation in exercise progressively encroached on maximal voluntary ventilation (MVV) with progressive dyspnea, due to both increases in ventilation and reductions in MVV. VE Volume of expired gas

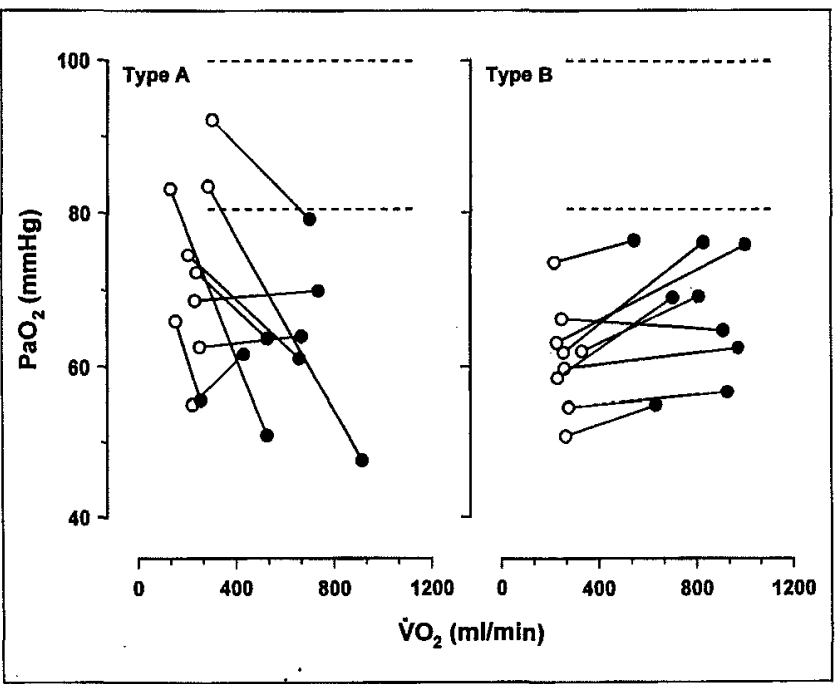

Figure 6) Arterial $\mathrm{PO}_{2}$ at rest and maximal steady state exercise in patients with type $A$ and $B$ syndromes. $\mathrm{PO}_{2}$ tends to be higher at rest but to fall to a greater extent in type $A$, whereas most type $B$ patients show an increase during exercise (19). $\mathrm{VO}_{2}$ Volume of expired oxygen

in the 'puffers' (type A); the 'bloaters' (type B), on the other hand, could often exercise surprisingly well, in the face of chronic hypercapnia, hypoxemia and right heart 'failure'. In spite of the work of Christie and his team showing that emphysema was associated with loss of elasticity and severe gas exchange impairment (6), the limiting factor at the time was thought to be mainly airflow obstruction as reflected in reductions in $\mathrm{FEV}_{1}$. But differences in $\mathrm{FEV}_{1}$ did not explain differences among patients in exercise capacity and dyspnea, and the thought arose that one could only discover the factors behind this variability by actually studying what happened during exercise. The opportunity presented itself as part of a joint study between the Hammersmith Hospital's Bronchitis Clinic and the University of Chicago's Emphysema Clinic -

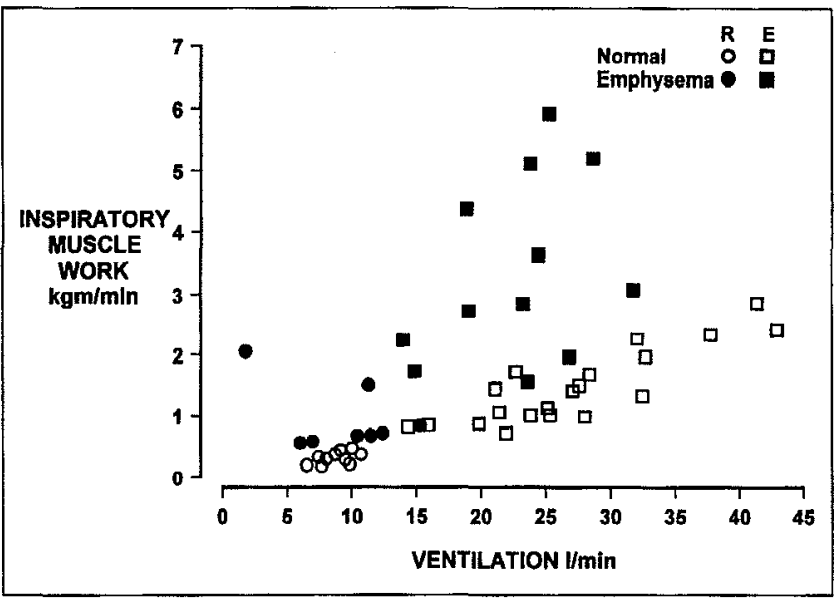

Figure 7) McIlroy and Christie's measurements of the mechanical work of breathing at rest $(R)$ and exercise $(E)$ in normal subjects and patients with emphysema (redrawn, from 7)

a comparison of 'British Bronchitis' with 'American Emphysema'. This study involved the careful characterization of 50 patients in each clinic, and as part of the Hammersmith effort we carried out a series of exercise studies, including a comparison of type A with type B patients. These studies (19) showed that, compared with type $\mathrm{B}$, type A patients were more limited, kept $\mathrm{PaCO}_{2}$ lower and showed a fall in $\mathrm{PaO}_{2}$ with exercise (Figure 6); they had a large $\mathrm{V}_{\mathrm{D}} / \mathrm{V}_{\mathrm{T}}$ and an alveolar-arterial (A-a) $P_{2}$ difference that increased. Type $\mathrm{B}$ patients showed a wide $\mathrm{A}-\mathrm{a} \mathrm{PO}_{2}$ difference at rest, but this narrowed with exercise, suggesting that areas in the lung with a low $V_{A} / Q_{c}$ ratio improved their ventilation equally with the overall increase in exercise ventilation. Our thought then was that this behaviour removed a hypoxic drive to breathe during exercise and contributed to chronic underventilation, but this was an oversimplification. More recently, the elegant multiple inert gas washout technique has been applied to type $\mathrm{A}$ and $B$ patients to confirm the dominant $V_{A} / Q_{c}$ patterns (23). The combination of improving, contrasted with worsening, $\mathrm{V}_{\mathrm{A}} / \mathrm{Q}_{\mathrm{c}}$ distribution, together with overall underventilation leads to ventilation being lower and dyspnea less prominent in the type $B$ patient.

\section{THE RESPIRATORY MUSCLES}

Christie, in defining dyspnea as an increase in the effort accompanying breathing, clearly identified the role of increased respiratory muscle work and oxygen consumption. Later, with Malcolm McIlroy, he measured intra-oesophageal pressure and $\dot{V}_{T}$, and calculated respiratory work at rest and exercise in normal subjects and patients with emphysema (7). At a given ventilation, the work was two to three times greater in patients (Figure 7) and "must at least be an important factor in the production of dyspnea". They also apportioned the work against the resistive and elastic impedances to breathing, to which are added the extra forces involved in expanding an already expanded chest and an inability to reduce end-expiratory lung, and thus to recruit normally the inspiratory outward recoil of the chest wall at low lung 


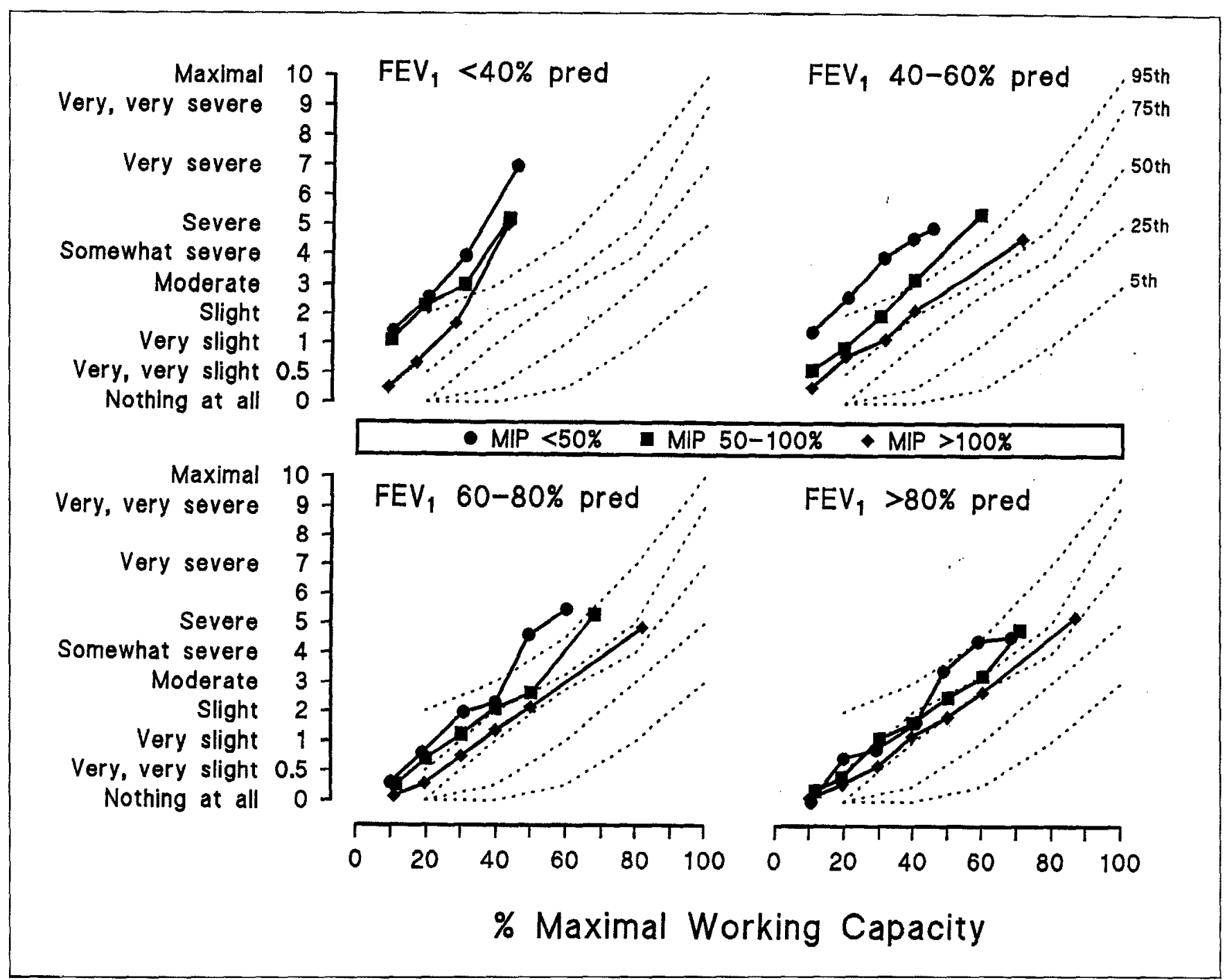

Figure 8) Borg rating scale applied to dyspnea in patients grouped according to reduction in forced expiratory volume in 1 s (FEV 1 ; each group is subdivided according to maximum inspiratory pressure (MIP) to show increasing perception of dyspnea with inspiratory muscle weakness (48). Working capacity is expressed as \% predicted (pred)

volume (Figure 3). The contribution of the last factor to dyspnea has recently been emphasized by O'Donnell (24).

The work of breathing in type $B$ patients was noted to be similar in type A by Howell (25), and thus unlikely to contribute to underventilation. The fact that this group of patients tends to be less dyspneic than type $A$ indicates a complex interaction between the work of breathing and the control of breathing in influencing overall ventilation and the sense of respiratory effort.

Studies of hyperventilation suggested that the oxygen cost of breathing during exercise could be as high as $1 \mathrm{~L} / \mathrm{min}$ in COLD (26). However, because in studies of loaded breathing to failure in healthy subjects oxygen uptake only increased by a mean of $142 \mathrm{~mL} / \mathrm{min}$ (27), and in patients with severe airflow limitation during exercise the increase in oxygen uptake above that expected for the power output is only 100 to $300 \mathrm{~mL} / \mathrm{min}(28)$, it seems likely that such values were overestimates, as suggested also by the measurements of Mcllroy and Christie.
While it is possible to load well-motivated healthy subjects to the point of respiratory failure and muscle fatigue, this is associated with extreme dyspnea that is unlikely to be tolerated during exercise in patients, who appear more likely to stop exercise or breathe less, before this point is reached. However, the role of respiratory muscle fatigue in generating dyspnea or in limiting increases in ventilation may still be important (29). Studies employing continuous positive airway pressure as an assist device in patients with COLD have shown that it may increase exercise performance (30) and reduce breathlessness (31).

\section{MECHANISMS OF DYSPNEA}

In a much-quoted introduction to a symposium on breathlessness in 1966, Comroe (32) predicted that few of the forthcoming speakers would actually deal with this symptom, and he was proved right. However, under the leadership of $\mathrm{Dr}$ Moran Campbell, who with Dr Jack Howell organized that symposium, threshold detection and later magnitude scaling 


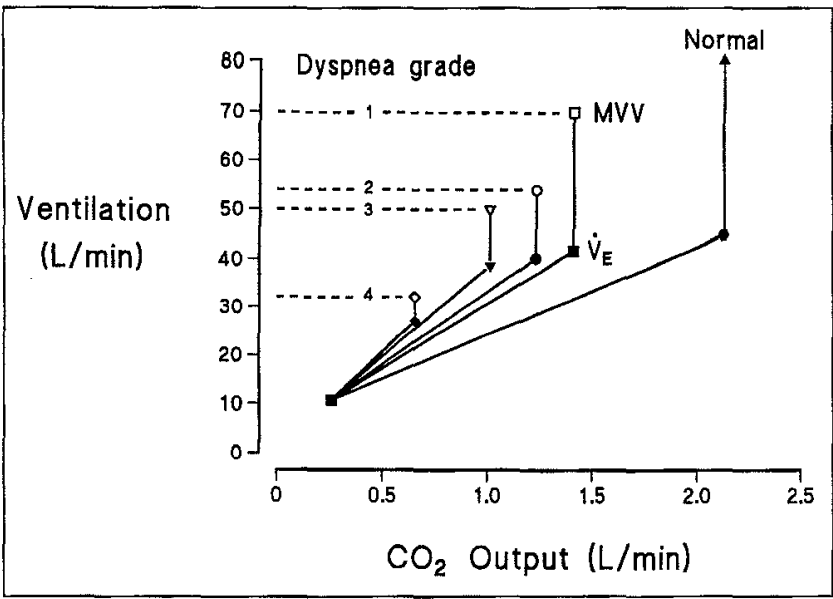

Figure 5) Ventilation in relation to carbon dioxide output in the same patients as in Figure 4; ventilation in exercise progressively encroached on maximal voluntary ventilation (MVV) with progressive dyspnea, due to both increases in ventilation and reductions in $M V V$. VE Volume of expired gas

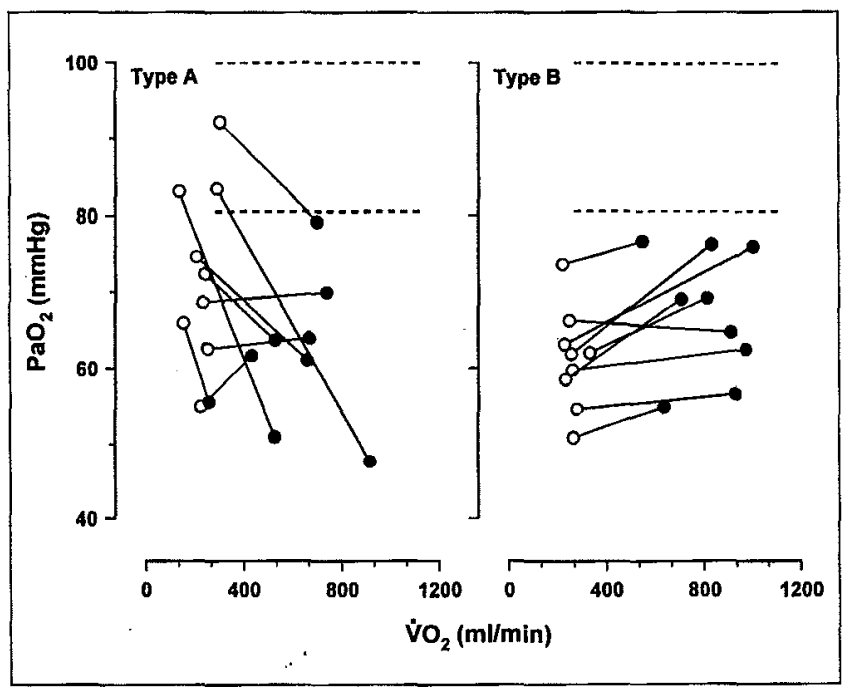

Figure 6) Arterial $\mathrm{PO}_{2}$ at rest and maximal steady state exercise in patients with type $A$ and $B$ syndromes. $\mathrm{PO}_{2}$ tends to be higher at rest but to fall to a greater extent in type $A$, whereas most type B patients show an increase during exercise (19). $\mathrm{V}_{2} 2$ Volume of expired oxygen

in the 'puffers' (type A); the 'bloaters' (type B), on the other hand, could often exercise surprisingly well, in the face of chronic hypercapnia, hypoxemia and right heart 'failure'. In spite of the work of Christie and his team showing that emphysema was associated with loss of elasticity and severe gas exchange impairment (6), the limiting factor at the time was thought to be mainly airflow obstruction as reflected in reductions in FEV 1 . But differences in FEV 1 did not explain differences among patients in exercise capacity and dyspnea, and the thought arose that one could only discover the factors behind this variability by actually studying what happened during exercise. The opportunity presented itself as part of a joint study between the Hammersmith Hospital's Bronchitis Clinic and the University of Chicago's Emphysema Clinic -

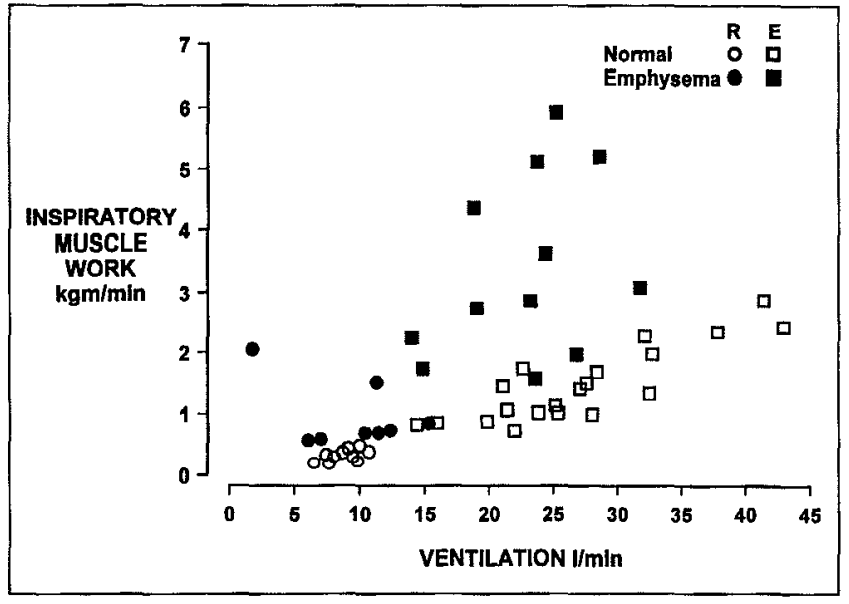

Figure 7) McIlroy and Christie's measurements of the mechanical work of breathing at rest $(R)$ and exercise $(E)$ in normal subjects and patients with emphysema (redrawn; from 7)

a comparison of 'British Bronchitis' with 'American Emphysema'. This study involved the careful characterization of 50 patients in each clinic, and as part of the Hammersmith effort we carried out a series of exercise studies, including a comparison of type A with type B patients. These studies (19) showed that, compared with type $\mathrm{B}$, type A patients were more limited, kept $\mathrm{PaCO}_{2}$ lower and showed a fall in $\mathrm{PaO}_{2}$ with exercise (Figure 6); they had a large $\mathrm{V}_{\mathrm{D}} / \mathrm{V}_{\mathrm{T}}$ and an alveolar-arterial (A-a) $P \mathrm{O}_{2}$ difference that increased. Type $\mathrm{B}$ patients showed a wide A-a $P_{2}$ difference at rest, but this narrowed with exercise, suggesting that areas in the lung with a low $V_{A} / Q_{c}$ ratio improved their ventilation equally with the overall increase in exercise ventilation. Our thought then was that this behaviour removed a hypoxic drive to breathe during exercise and contributed to chronic underventilation, but this was an oversimplification. More recently, the elegant multiple inert gas washout technique has been applied to type $A$ and $B$ patients to confirm the dominant $\mathrm{V}_{\mathrm{A}} / \mathrm{Q}_{\mathrm{c}}$ patterns (23). The combination of improving, contrasted with worsening, $\mathrm{V}_{\mathrm{A}} / \mathrm{Q}_{\mathrm{c}}$ distribution, together with overall underventilation leads to ventilation being lower and dyspnea less prominent in the type B patient.

\section{THE RESPIRATORY MUSCLES}

Christie, in defining dyspnea as an increase in the effort accompanying breathing, clearly identified the role of increased respiratory muscle work and oxygen consumption. Later, with Malcolm Mcllroy, he measured intra-oesophageal pressure and $\dot{V}_{T}$, and calculated respiratory work at rest and exercise in normal subjects and patients with emphysema (7). At a given ventilation, the work was two to three times greater in patients (Figure 7) and "must at least be an important factor in the production of dyspnea". They also apportioned the work against the resistive and elastic impedances to breathing, to which are added the extra forces involved in expanding an already expanded chest and an inability to reduce end-expiratory lung, and thus to recruit normally the inspiratory outward recoil of the chest wall at low lung 


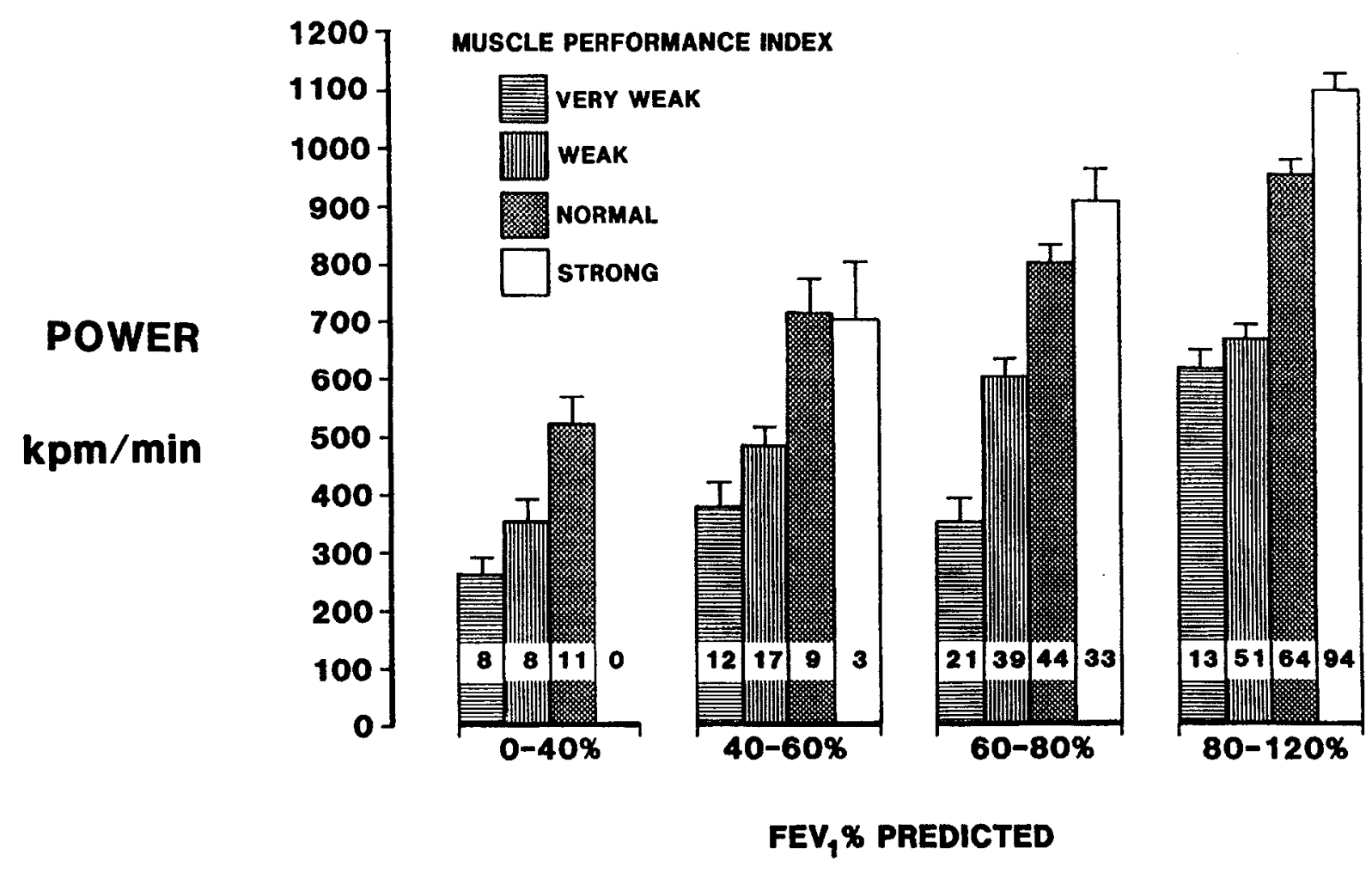

Figure 9) Histograms of maximum power output in patients grouped according to forced expiratory volume in $1 s$ (FEV 1 ), with subgrouping according to skeletal muscle strength measurement, to show contribution of muscle weakness to reductions in exercise capacity (37)

began to be applied to this distressing sensation (33), and the subsequent 25 years has seen the progressive expansion of research in this field. At the time they organized the symposium Campbell and Howell had for a number of years developed the concept of 'length-tension inappropriateness' as underlying dyspnea (34). The proprioceptive neurophysiology was to many of us who trained under Dr Campbell hard to understand, but at some levels provided a more inclusive explanation for dyspnea than could be found elsewhere. Thus, at one level, patients with dyspnea sensed discomfort because the ventilation and associated effort were inappropriate to level of exercise being accomplished when related to their past experience.

After Dr Campbell came to McMaster University, he continued his loaded breathing studies and later was joined by Kieran Killian; since then, over a number of years they have employed the sensory magnitude as a dependent variable that is quantitatively influenced by many factors acting in concert. Studies of respiratory loading, resistive and elastic, at rest $(27,35)$ and during exercise $(36)$, established the importance of increases in carbon dioxide output; ventilation; $\mathrm{V}_{\mathrm{T}}$ in relation to vital capacity; reductions in pleural pressures in relation to the maximal pressure generating capacity, representing the strength of respiratory muscles; and increasing frequency of breathing. Increases in end-inspiratory lung volume, representing the extent of muscle shortening, and increasing inspiratory flow, representing the velocity of contraction, were also shown to contribute by reducing the force generating capacity of the inspiratory muscles through their force-velocity and length-tension relationships: a $3 \%$ increase in volume above functional residual capacity and $1 \mathrm{~L} / \mathrm{s}$ increase in inspired flow both reduced this capacity by $5 \%$ (37). On the basis of these studies in healthy subjects, similar principles were applied in cardiorespiratory disorders to identify similar factors in them (38). Many of these factors were relatively predictable on the basis of the forces that have to be generated to achieve ventilation and of the general properties of muscle. Less predictable was the importance of variation in respiratory muscle strength. Respiratory muscle weakness contributed substantially to the sense of respiratory effort in patients with varying degrees of airflow limitation (Figure 8) (37). More recently its importance in patients with heart failure has been emphasized (39).

\section{WHAT LIMITS PATIENTS WITH COLD IN EXERCISE?}

The capacity to exercise used to be examined in terms of motor function and its impairment, but now we have good reasons for accepting an important role for the sensory cortex as well, in terms of limiting exercise when the sensation has risen to unacceptable intensities. Soon after Killian had shown how much information could be gained by considering sensory information during exercise, we began to use the Borg psychophysical rating scale to measure sensory intensities during routine clinical exercise tests (40). Although shown to be very useful and valid in scaling respiratory 
muscle effort in the studies described above, Gunnar Borg (41) had initially developed and validated the scale to enable measurement of skeletal muscle effort during exercise; compared with other scaling techniques it showed distinct advantages in conforming to Stevens' Power Law (42), in having ratio properties and in providing a category scale that allowed absolute magnitudes to be compared among subjects. Thus, in routine exercise studies, the intensity of both skeletal muscle effort and the effort related to breathing may be separately scaled. After only a short time, it became apparent that, among patients with respiratory disorders, some $30 \%$ were not limited by dyspnea but by the intensity of leg muscle effort (37). Furthermore, measurements of leg muscle strength indicated that leg muscle weakness contributed to this limitation. Thus, the incidence of weakness increased with increasing airflow limitation (Figure 9) and contributed to the intensity of effort and limitation of exercise capacity (43). It appears that, in many patients with cardiorespiratory disorders, enforced inactivity contributes to weakness and to down-regulation of muscle oxidative enzymes $(18,44)$, which separately contribute to their disability. The finding of respiratory and skeletal muscle weakness as major contributors to exercise limitation suggests that muscle strengthening, particularly when targeted towards the weaker patients, would be helpful. Although it used to be thought that strength or weight training was 'specific' in its effects, only improving strength, this conclusion was reached on the basis of studies in athletes; in less-trained

ACKNOWLEDGEMENTS: I am grateful to Dr W Thurlbeck for the photograph of Dr Christie, and to Dr Jonathan Meakins III for that of his grandfather. Our work has been supported by the Medical Research Council, the Ontario Heart and Stroke Foundation, and the Canadian and Ontario Thoracic Societies.

\section{REFERENCES}

1. Meakins JC, Davies HW. Respiratory Function in Disease. Edinburgh: Oliver and Boyd, 1925.

2. Meakins J, Christie RV. Treatment of emphysema. JAMA 1934;103:384-7.

3. Christie RV. The elastic properties of the emphysematous lung and their clinical significance. J Clin Invest 1934;13:295-309.

4. Christie RV. Emphysema of the lungs. BMJ 1944;i:106-8.

5. Christie RV. Dyspnoea: a review. Q J Med 1938;27:421-54.

6. Bates DV, Knott JMS, Christie RV. Respiratory function in emphysema in relation to prognosis. Q J Med 1956;25:137-57.

7. Mcllroy MB, Christie RV. The work of breathing in emphysema. Clin Sci 1954:13:147-54.

8. Stratton JR, Levy WC, Schwartz RS, Abrass IB, Cerqueira MD. Beta-adrenergic effects on left-ventricular filling - influence of aging and exercise training. J Appl Physiol 1994;77:2522-9.

9. Baldwin E deF, Cournand A, Richards DW. Pulmonary insufficiency. I. Physiological classification, clinical methods of analysis, standard values in normal subjects. Medicine 1948;27:243-78.

10. Hugh-Jones P, Lambert AV. A simple standard exercise test and its use for measuring exertion dyspnoea. BMJ 1952;i:65-71.

11. Armstrong RB, Workman JM, Hurt HH, Roemich WR. Clinicophysiologic evaluation of physical working capacity in persons with pulmonary disease. Part 1. Am Rev Respir Dis 1966;93:90-9.

12. Freedman S. Sustained maximum voluntary ventilation. Respir Physiol $1970 ; 8: 230-44$

13. Clark TJH, Freedman S, Campbell EJM, Winn RR. The ventilatory capacity of patients with chronic airway obstruction. Clin Sci 1969;36:307-16.

14. Killian KJ, Inman MD, Jones NL. The thorax in exercise. In: Roussos individuals there is considerable overlap in the effects of strength training. Weight training has improved both strength and endurance of patients with COLD (45) and cardiac failure (46), with a disproportionate improvement in their quality of life.

\section{CONCLUSION}

Meakins and Christie realized that many factors contributed to dyspnea and limited exercise capacity, and that to manage our patients effectively the interactions need to be understood and measured. This applies not only to their main interest, emphysema, but also to cardiac failure; Christie (5) was in agreement with his eminent contemporary, Sir Thomas Lewis: "The first indication of cardiac failure is to be found in a diminished tolerance of exercise. Of the very numerous tests of cardiac efficiency and inefficiency that have been devised, based as they are mainly upon pulse-rate or upon blood-pressure or upon both, there is none that approach in delicacy the symptom of breathlessness" (47). Nowadays if the question is asked as to what limits patients' capacity to exercise, the logical answer is that the same factors limit patients as healthy subjects, but at a lower level of activity and with a different weighting of contributory factors. Thus, it seems possible that the field of integrative physiology will be an increasingly fertile source of ideas and strategies in patient management. Jonathan Meakins and Ronald Christie would be glad to know that their seminal work continues to bear fruit.

CS, ed. The Thorax. Part B: Applied Physiology. New York: Marcel Dekker Inc, 1995:1355-72.

15. Jones NL, Haddon RWT. Effect of a meal on cardio-pulmonary and metabolic changes during exercise. Can J Physiol Pharmacol 1973;51:445-50.

16. Brown SE, Weiner S, Brown RA. Exercise performance following a carbohydrate load in chronic airflow obstruction. J Appl Physiol 1985;58:1340-6

17. Taylor $\mathrm{R}$, Jones NL. The reduction by training of $\mathrm{CO}_{2}$ output during exercise. Eur J Cardiol 1979;9:53-62.

18. Maltais F, Simard A-A, Simard C, Jobin J, Desgagnes P, Leblanc P. Oxidative capacity of the skeletal muscle and lactic acid kinetics during exercise in normal subjects and in patients with COPD. Am J Respir Crit Care Med 1995;153:288-93.

19. Jones NL. Pulmonary gas exchange during exercise in patients with chronic airflow obstruction. Clin Sci 1966;31:39-50.

20. Kilburn KH. Evaluation of impairment and disability in patients with bronchitis and emphysema. In: Cherniack NS, ed. Chronic Obstructive Pulmonary Disease. Philadelphia: WB Saunders \& Co, 1991:560-8.

21. Jones NL. Pulmonary gas exchange during exercise. MD Thesis, University of London, 1964.

22. Burrows B, Fletcher CM, Heard BE, Jones NL, Wootliff JS. The emphysematous and bronchial types of chronic airways obstruction: a clinical pathological study of patients in London and Chicago. Lancet 1966;i:830-5.

23. Wagner PD. Effects of COPD on gas exchange. In: Cherniack NS, ed. Chronic Obstructive Pulmonary Disease. Philadelphia: WB Saunders \& Co, 1993:73-9.

24. O'Donnell DE. Breathlessness in patients with chronic airflow limitation. Chest 1994;106:904-12.

25. Howell JBL. Breathlessness in pulmonary disease. In: Howell JBL, Campbell EJM, eds. Breathlessness. Oxford: Blackwell Scientific Publications, 1966:165-77.

26. Levison $\mathrm{H}$, Cherniack RM. Ventilatory cost of exercise in chronic obstructive pulmonary disease. J Appl Physiol 1968;25:21-7.

27. Jones GL, Killian KJ, Summers E, Jones NL. Inspiratory muscle forces and endurance in maximal resistive loading. J Appl Physiol 
$1985 ; 58: 1608-15$

28. Jones NL, Jones G, Edwards RHT. Exercise tolerance in chronic airway obstruction. Am Rev Respir Dis 1971;103:477-91.

29. Grassino AE. Limits of maximal inspiratory muscle function. In: Jones NL, Killian, KJ, eds. Breathlessness. The Campbell Symposium. Burlington: Boehringer-Ingelheim, 1992:27-33.

30. O'Donnell DE, Sanii R, Younes M. Improvement in exercise endurance in patients with chronic airflow limitation using continuous positive airway pressure. Am Rev Respir Dis 1988;138:1510-4.

31. O'Donnell DE, Sanii R, Giesbrecht G, Younes M. Effect of continuous positive airway pressure on respiratory sensation in patients with chronic obstructive pulmonary disease during submaximal exercise. Am Rev Respiratory Dis $1988 ; 138: 1185-91$.

32. Comroe JH Jr. Some theories on the mechanism of dyspnoea. In: Howell JBL, Campbell EJM, eds. Breathlessness. Oxford: Blackwell Scientific Publications, 1966:1-7.

33. Killian KJ, Mahutte CK, Campbell EJM. Magnitude scaling of externally added loads to breathing. Am Rev Respir Dis 1981;123:12-5.

34. Campbell EJM, Howell JBL. The sensation of breathlessness. Br Med Bull 1963;19:36-40.

35. Jones GL, Killian KJ, Summers E, Jones NL. The sense of effort, oxygen cost and pattern of breathing associated with progressive elastic loading to fatigue. Fed Proc 1984;42:1420. (Abst)

36. El-Manshawi A, Killian KJ, Summers E, Jones NL. Breathlessness during exercise with and without resistive loading. J Appl Physiol 1986;61:896-905.

37. Jones NL, Killian KJ. Limitation of exercise in chronic airway obstruction. In: Cherniack NS, ed. Chronic Obstructive Pulmonary Disease. Philadelphia: WB Saunders \& Co, 1991:196-206.

38. Leblanc P, Bowie DM, Summers E, Jones NL, Killian KJ. Breathlessness and exercise in patients with cardiorespiratory disease. Am Rev Respir Dis 1986;133:21-5.

39. McParland C, Krishnan B, Wang Y, Gallagher CG. Inspiratory muscle weakness and dyspnea in chronic heart failure. Am Rev Respir Dis 1992;146:467-72.

40. Jones NL. Clinical Exercise Testing, 3rd edn. Philadelphia: WB Saunders \& Co, 1988.

41. Borg GAV. Psychophysical bases of perceived exertion. Med Sci Sports Exerc 1982;14:377-81.

42. Stevens SS. On the psychophysical law. Psychol Rev 1957;64:153-81.

43. Killian KJ. Symptoms limiting exercise. In: Jones NL, Killian KJ, eds. Breathlessness. The Campbeli Symposium. Burlington: Boehringer-Ingelheim, 1992:132-42.

44. Wilson JR, Mancini DM. Factors contributing to the exercise limitation of heart-failure. J Am Coll Cardiol 1993;22:A93-8.

45. Simpson K, Killian KJ, McCartney N, Stubbing DG, Jones NL. Randomized controlled trial of weightlifting exercise in patients with chronic airflow limitation. Thorax 1992;47:70-5.

46. McKelvie RS, Teo KK, McCartney N, Humen D, Montague T, Yusuf $\mathrm{S}$. Effects of exercise training in patients with congestive heart failure A critical review. J Am Coll Cardiol 1995;25:789-96.

47. Lewis T. Diseases of the Heart. London: McMillan \& Co, 1937.

48. Killian KJ, Jones NL. Mechanisms of exertional dyspnea. Clin Chest Med 1994;15:247-57. 


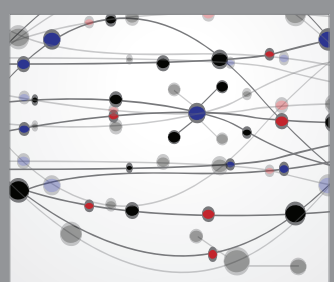

The Scientific World Journal
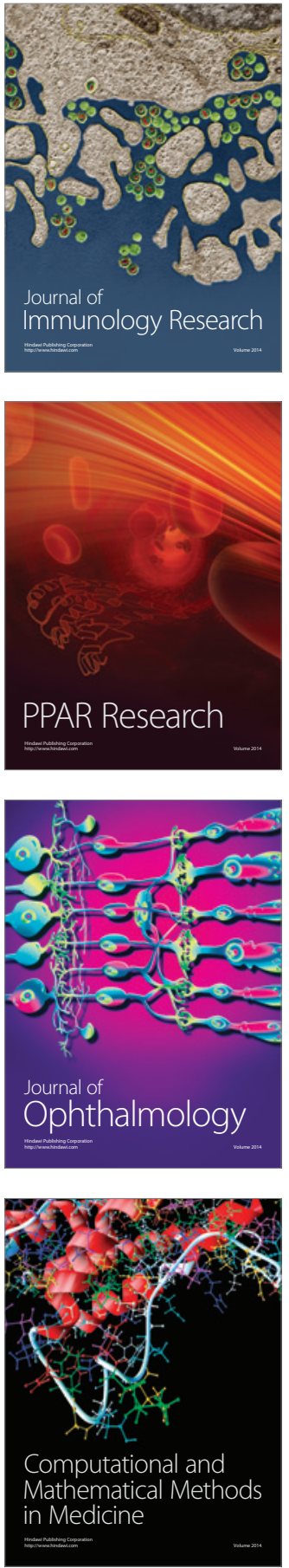

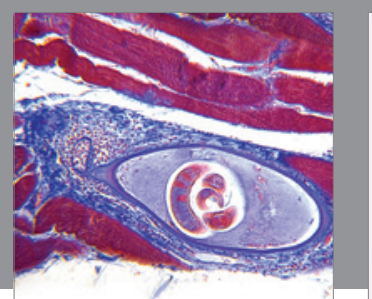

Gastroenterology Research and Practice

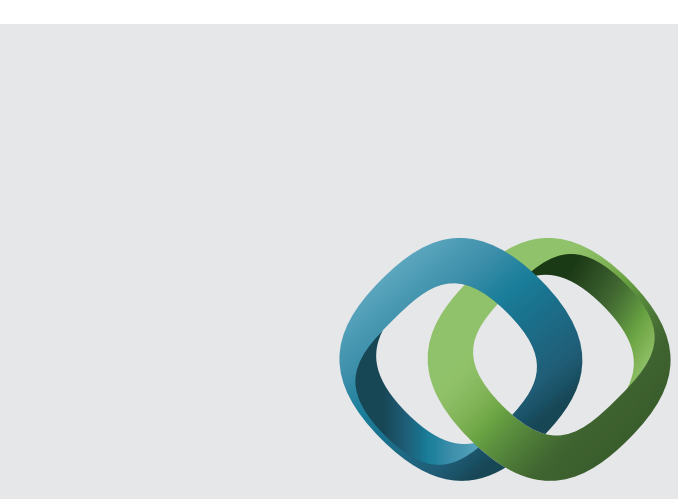

\section{Hindawi}

Submit your manuscripts at

http://www.hindawi.com
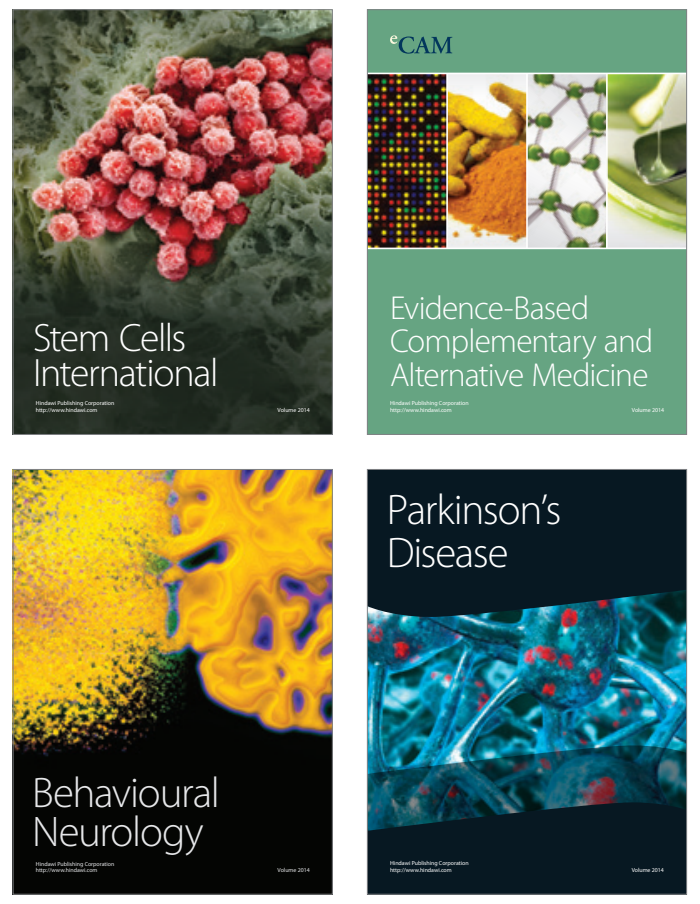
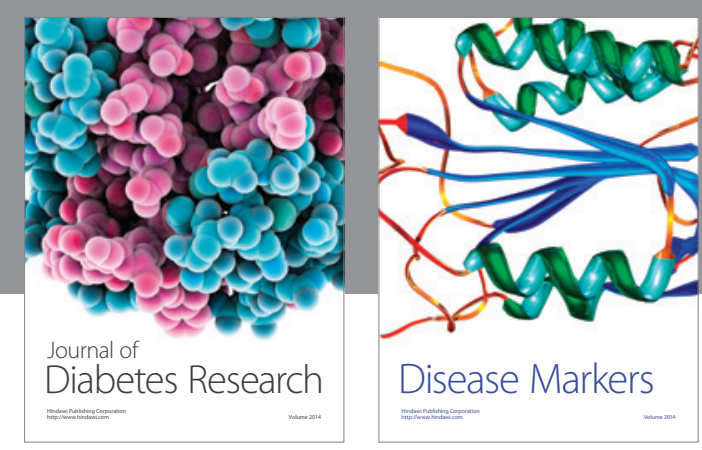

Disease Markers
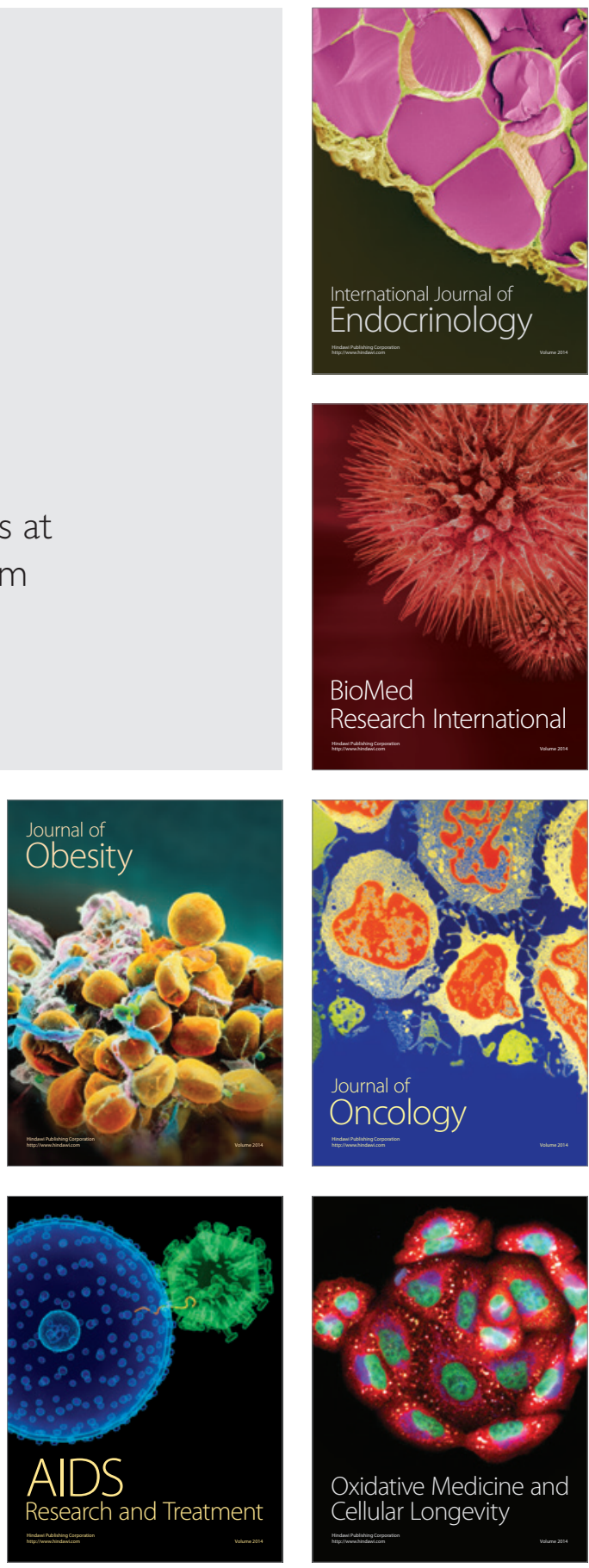